Int. J. Electrochem. Sci., 12 (2017) 10737 - 10748

\title{
Fabrication of a New Carbon Paste Electrode Based on 5,11,17,23-tetra-tert-butyl-25,27-bis(pyren-1-yl-methylimido- propoxy)-26,28-dihydroxy-calix[4]arene for Potentiometric Perchlorate Determination
}

\author{
H. Elif Kormall Ertürün \\ Department of Chemistry, Faculty of Science, Ankara University, Tandoğan 06100, Ankara, Turkey \\ E-mail: kormali@science.ankara.edu.tr
}

doi: $10.20964 / 2017.11 .21$

Received: 30 June 2017 / Accepted: 28 August 2017 / Published: 12 October 2017

\begin{abstract}
A new perchlorate-selective carbon paste electrode based on a calix[4]arene derivative was prepared and evaluated in terms of construction, performance, and applications. The optimum carbon paste combination was specified as $30.0 \%$ ionophore, $30.0 \%$ graphite powder, and $40.0 \% 2$-nitrophenyloctyl ether as binder. The proposed electrode showed a near-Nernstian slope of $56.3 \pm 0.6 \mathrm{mV} / \mathrm{pClO}_{4}$ in the concentration range of $1.0 \times 10^{-6}-1.0 \times 10^{-1} \mathrm{M}$ over the wide $\mathrm{pH}$ range. It has relatively short response time (6-8 s) and a long lifetime (at least 18 months). The selectivity sequence of the electrode was given according to the coefficients calculated by SSM. Furthermore, perchlorate ions in tap water, river water and human urine samples were successfully determined by direct potentiometry and the resulting mean recoveries were found in the order of $99.4 \%, 99.8 \%$ and $99.1 \%$. Therefore, the proposed perchlorate-selective carbon paste electrode could be an alternative indicator electrode for potentiometric perchlorate analysis.
\end{abstract}

Keywords: Calix[4]arene; Carbon paste electrode; Potentiometry; Perchlorate-selective electrode; Determination of perchlorate

\section{$\underline{\text { FULL TEXT }}$}

(C) 2017 The Authors. Published by ESG (www.electrochemsci.org). This article is an open access article distributed under the terms and conditions of the Creative Commons Attribution license (http://creativecommons.org/licenses/by/4.0/). 